\title{
LECTURA EN EL NIVEL INICIAL
}

Patricia Correa, Rossana Gutiérrez y Mabel Patetta

\section{DEFINICIÓN DEL PROBLEMA}

"Recientemente se ha comenzado a cobrar conciencia de la importancia de la alfabetización inicial como única solución de fondo al problema de la alfabetización remedial (de adolescentes y adultos). Tradicionalmente la alfabetización inicial se ha planteado en función de la relación entre el método utilizado y el estado de madurez o de prontitud del niño."

Ferreiro (1988: 9)

Como docentes de Educación Inicial nos sentimos altamente comprometidas con esta afirmación. Estamos de acuerdo con lo allí mencionado; esta situación despierta en nosotras la preocupación de poder desarrollar al máximo el potencial del niño para el aprendizaje de la LECTURA en su lengua materna.

Consideramos que el entorno provee al niño de vivencias que lo motivan a acercarse al mundo de los adultos, ese mundo lleno de códigos que él aún no siempre comprende. Nos resulta difícil pensar e incluso imaginar, en este ambiente urbano, a niños de cuatro y cinco años que no tengan una idea sobre la naturaleza de ese" objeto cultural", denominado lengua. En ese ambiente que rodea a esos niños encuentran textos escritos por todas partes: en sus juguetes, en su ropa, en los carteles publicitarios, en sus libros de cuento, en la televisión, etc. Nos resulta difícil, reiteramos, imaginar que, esos niños que plantean las preguntas más difíciles de responder, que se interrogan acerca de todos los fenómenos que observan, no tengan inquietudes por aprender a leer, como lo expresan Vieytes y López: "...el niño curioso, activo y creador por naturaleza, se enfrenta desde temprano con la escritura, con este tipo particular de grafías diferentes al dibujo, que están presentes en el medio, dentro y fuera de sus hogares. En los medios urbanos, esto sucede con la señalización de las calles, carteles de propaganda, anuncios, etiquetas y todo tipo de mensajes escritos... El niño se enfrenta pues precozmente, con un objeto que irá tratando de comprender: el sistema de escritura" (1992:40).

\section{2 . PREGUNTAS DE INVESTIGACIÓN}

La intención es determinar de qué forma realizan la enseñanza de la Lectura las docentes de los niveles 4 y 5 años (Nivel Inicial) de la Institución donde desempeñamos nuestra labor; nos preguntamos:

1) ¿Cuáles son las estrategias, los métodos y técnicas que han sido más favorables para estimular la lectura en el niño?.

2) ¿Cuáles son las estrategias, métodos o técnicas que se utilizan en nuestra Institución?

3) ¿Qué relación se puede establecer entre estas estrategias, métodos, técnicas establecidas luego del rastreo bibliográfico y las aplicadas dentro de nuestra Institución? 


\section{MARCO TEÓRICO}

\section{1 ¿Qué es leer?}

Leer no es sólo un esfuerzo perceptivo, un decodificar símbolos gráficos en palabras, ya que esto lleva a pensar que la lectura es un hecho pasivo, mecánico, una simple técnica de descifrado, donde el lector automáticamente comprendería al autor. Las nuevas concepciones ponen el acento en la participación activa del lector, quien aporta todo su bagaje, sus experiencias, conocimientos, vivencias y expectativas para la comprensión y recreación del significado de lo que lee.

Es un proceso activo y complejo que permite la interpretación de signos de un código escrito, de acuerdo con las vivencias personales, produciendo intercambios entre el lector y mensaje leído.

Leer es ser capaz de interpretar, criticar, captar las ideas que están explícitas en un texto y la intención implícita de su autor, comprender más allá del significado literal: captar el sentido. Las concepciones actuales coinciden en entender la lectura no como una habilidad, sino básicamente como una actitud.

Saber leer no es decodificar, declamar, deletrear. Saber leer es anticipar, sintetizar, sustituir, adivinar las intenciones del texto, de su autor y por supuesto, abandonar la absurda creencia de que todas las palabras del texto tienen el mismo valor: algunos libros tienen una sola idea hay que saber descubrirla.

Es sabido que cuando leemos el ojo no barre todas las letras. Seleccionamos y anticipamos el resto. Este procedimiento recibe el nombre de "muestreo" también predecimos lo que vendrá a continuación, en función de los datos siguientes y de nuestra competencia lingüística, corroboraremos si nuestras anticipaciones son correctas; en caso contrario, procederemos a autocorregirnos. Concebir un acto de lectura de esta manera determina un accionar pedagógico particular que, por cierto, no va a consistir en "enseñar" las letras y correspondientes sonidos, sino en plantear a los niños situaciones que estimulen y demanden la utilización de estas estrategias al enfrentar un texto escrito.

Los trabajos de Ferreiro referidos a la lectura ponen en evidencia que desde muy temprano el niño es capaz de anticipar el significado de un texto a partir de sus conocimientos previos, a partir de la imagen que acompaña a la escritura, a partir de las características del portador del texto. Señala Ferreiro en una de sus obras: "las primeras interpretaciones de textos son enteramente dependientes de dos condiciones una externa ( ej. contexto ) y otra interna (la idea de que los nombres es lo que está escrito). Esta idea infantil - a la que llama hipótesis del nombre - seguirá vigente por mucho tiempo y sin embargo las relaciones entre contexto y el texto irán variando ...” $(1988: 77)$.

En la entrevista realizada por Mérega a Kaufman, ésta expresa "los chicos que todavía no saben leer de manera convencional hacen lo mismo que los buenos lectores adultos: tratan de coordinar la información de los textos escritos con los datos que suministra el contexto a fin de acceder a la significación.

Lógicamente, los chicos conocen menos de la legalidad que rige los textos, es decir, cuales son los elementos del sistema de escritura, cuales sus reglas de formación... y por esa razón, se guían más por el contexto que por el texto mismo. Al comienzo casi no toman en consideración la información que provee el texto y basan su interpretación en las características del contexto. . Y Y aquí aparece una de las grandes paradojas de los métodos tradicionales para enseñar a leer y a escribir que consiste en la presentación de escrituras descontextuadas." (1989:8).

34 - Universidad ORT Uruguay 
Dada nuestra experiencia en la labor como docentes de Educación Inicial, nos adherimos a estas posturas vertidas por las autoras antes mencionadas. En la tarea diaria del aula, la presentación de lecturas acompañadas de un contexto significativo para el niño fueron las más atractivas y por ende las que nos dieron mejores resultados, en oposición a la presentación de lecturas descontextualizadas que no los atraían tanto como las antes mencionadas.

No debemos desconocer que desde pequeños los niños utilizan diferentes formas para comunicarse; sus primeros lenguajes no tienen las características del alfabético: sus actitudes, mímicas o gestos, incluso el dibujo, tienen un aspecto figurativo que no encontramos en el lenguaje escrito. Antes de su escolaridad, ya el niño en edad preescolar tiene una amplia experiencia en leer, refiriéndonos a la lectura de imágenes.

\subsection{Cómo insertar la lectura en el nivel inicial:}

"Para comprender a los niños debemos escuchar sus palabras, seguir sus explicaciones, entender sus frustraciones y atender a su lógica" expresado por Ferreiro y Teberosky, citado por Goodman (1991:9)

Descubrir lo que los niños saben sobre la lectura es algo que por mucho tiempo ha ocupado a los investigadores interesados por el lenguaje. Maestros e investigadores, en diferentes situaciones, observaban cómo los niños leían libros, envases, carteles; cómo usaban lápices y crayolas para expresar sus significados, llegando a la siguiente conclusión: aun antes de los cinco años, los niños saben mucho acerca del lenguaje; en el pasado los currículos oficiales determinaban que el primer año escolar ( 6 años) era el momento justo para enseñar a leer a los niños, pero hoy día esa idea afortunadamente ha cambiado.

Smith dice que "la lectura y el aprendizaje de la lectura no plantean ninguna demanda exorbitante" (1990: 194); todo consiste en leer más, logrando extraer ciertas conclusiones básicas para desarrollarse como lectores. La lectura no exige una maduración especial, por eso muchos niños en la etapa inicial ya han conseguido leer.

Autores como Smith (1990), Behar(1997), Goodman (1991) entre otros, coinciden en señalar que los niños que no saben leer, de manera convencional; tratan de coordinar la información de los textos guiándose más por el contexto que por el texto mismo. Al comienzo, casi no toman en consideración la información que provee el texto y basan su interpretación en las características del contexto.

En esta primera etapa del niño, el aprender a leer es un juego; como docentes no debemos desconocer la importancia de ofrecerle materiales sobre los cuales pueda formularse preguntas que sean significativas para él, ya que éste buscará en el texto escrito o impreso la información requerida para responder a las preguntas formuladas.

La lectura depende bastante más de lo que hay detrás de los ojos : de la información no visual más que de la información visual enfrente a ellos. Como maestros de Educación Inicial debemos procurar que la sala de clase sea un lugar donde el alumno pueda desarrollar actividades de lectura significativas y útiles, donde pueda participar sin ser evaluado ni presionado, donde pueda ser ayudado y colabore con sus pares, para ir adentrándose en el mundo de los lectores. Debemos ser los facilitadores de caminos de la lectura, garantizando que la misma tenga sentido, acercando al niño a ella de una manera placentera, útil y frecuente. Se le debe leer, contar cuentos, poemas, rimas; traer al aula materiales escritos que tengan algún sentido para el niño, en el mundo real y en el mundo que lo rodea, así como también saber aceptar todo aquello que él pueda aportar, dado que esto será de un valor afectivo tan importante que lo motivará cada vez más a avanzar por esa senda lectora. 


\section{OBJETIVOS}

\section{Objetivo General}

Contribuir al mejoramiento de la tarea educativa de los docentes de nivel 4 y 5 años de nuestro colegio, presentando las estrategias, métodos y técnicas utilizadas actualmente para la enseñanza de la lectura, que más se adapten a la realidad de esta institución.

\section{Objetivos Específicos}

1)__ Determinar las estrategias, métodos y técnicas aplicadas en la actualidad para enseñar y estimular la Lectura en el Nivel Inicial.

2)__ Identificar las estrategias que utilizan dentro del aula los maestros de los niveles 4 y 5 años de nuestro colegio para desarrollar en sus alumnos el interés por la Lectura.

\section{DISEÑO METODOLÓGICO}

Nos abocamos a realizar un estudio para determinar de qué forma las docentes de los niveles 4 y 5 años (Nivel Inicial) de nuestro colegio realizan la enseñanza de la lectura. La investigación se realizó en nuestra propia institución de trabajo, un colegio privado trilingüe (español -italiano- inglés).El mismo se encuentra ubicado en una zona residencial de Montevideo, su alumnado pertenece a familias de clase media y media alta. Los sujetos de investigación fueron todas las docentes del área español de los niveles 4 y 5 años titulares de grupo.

Adoptamos un enfoque de tipo cualitativo. Este trabajo de investigación se refiere a un sistema de triangulación: de información y de investigadoras para dar confiabilidad a la información recabada. La misma ha sido basada en métodos cualitativos como la observación, las entrevistas y análisis de los datos descriptivos.

\subsection{Instrumentos para la recolección de datos:}

_ Observación directa de las clases de español en el área del lenguaje en los niveles 4 y 5 años.

_Entrevistas a los docentes observados.

_Análisis comparativo de los datos obtenidos en los puntos precedentes.

Establecimiento de los elementos discordantes y concordantes de las estrategias, métodos y técnicas aplicadas por los docentes y las establecidas en el relevamiento bibliográfico.

La contrastación de los datos obtenidos por los diferentes métodos permitirá detectar y corregir la parcialidad de cada uno y depurar el valor de la información recabada. El examen cruzado de ellos permitirá paliar las limitaciones que encierra su análisis por separado. La secuencia que se consideró más conveniente fue la siguiente: 
_ Observación directa de la actividad de clase, llevando dos tipos diferentes de registro:

un registro con notas de campo en forma directa.

una ficha con items post- registro. La misma se completa finalizada la actividad.

_ Entrevista en profundidad a los docentes de español de los niveles 4 y 5 años de

nuestra Institución escolar.

\subsection{Colecta de datos}

La colecta de datos fue realizada durante el período octubre-diciembre de 1997. Se observaron y entrevistaron todas las docentes del área español de los niveles 4 y 5 años; en total cinco docentes, dos de nivel 4 y tres de nivel 5 .

Las observaciones se realizaron en el período comprendido entre los meses de octubre y noviembre; su número osciló entre seis y nueve, según el nivel de edad de los alumnos. Las notas de campo fueron transcriptas y se desarrollaron conceptos y proposiciones para dar sentido a los datos; se compararon los mismos, estableciendo las relaciones o discrepancias de las docentes según el nivel en que desarrollan su actividad.

Con respecto a las entrevistas queremos señalar que se utilizaron recursos tecnológicos de audio; este procedimiento en ningún momento representó un agente intimidatorio para el entrevistador o el entrevistado. La duración de la sesión varió entre los veinte y treinta minutos. Las entrevistas fueron transcriptas y a través de la lectura profunda de las mismas se establecieron las categorías, como un modo de codificar los datos cualitativos .

Fuimos elaborando un resumen con las ideas fundamentales de cada entrevista y se trató de interpretar qué aspectos describía y resaltaba cada docente y se establecieron los elementos comunes entre ellas.

Una vez estudiados y analizados estos datos por separado, se procede a la constrastación de los mismos en forma simultánea, estableciendo si las categorías emergentes de las entrevistas coinciden con los conceptos y proposiciones establecidas en las observaciones realizadas a cada maestra.

\section{REFLEXIONES SOBRE EL ANÁLISIS DE LOS DATOS OBTENIDOS}

Finalizada la etapa de investigación, colecta y análisis de los datos, se pudo establecer que las docentes integrantes sujetos de la Investigación son todas egresadas de el Instituto Normal de Educación Primaria, su egreso de esta carrera fue entre finales de la década del 80 y el correr de la década del 90. Esto determinó que la mayoría de las maestras estuvieran en conocimiento de las nuevas tendencias acerca de la enseñanza de la Lectura.

A continuación detallamos los aspectos coincidentes del análisis: 


\section{Con respecto a las docentes:}

* Se pudo establecer a través de las observaciones y de las entrevistas la idea de las docentes con respecto al proceso de adquisición de la Lectura y la Escritura. Todas ellas distinguen estos procesos como dos aspectos diferentes del quehacer educativo que no necesariamente deben ir juntos, y que no trabajan siempre juntos.

* Establecen la necesidad de incorporar la idea de los aprendizajes significativos como medio para motivar el interés de los educandos. Para lograr esto tienen en cuenta los aportes escolares y los extraescolares.

* Consideran que aprender a leer es importante. No se debe forzar al niño a aprender; se lo debe motivar e incentivar con diferentes recursos, técnicas variadas y respetando sus ritmos de aprendizaje. De las observaciones se desprende que las docentes presentaban en las actividades propuestas recursos variados, respetando las diferencias y los intereses individuales de los alumnos en el quehacer del aula.

* Piensan que la familia y el entorno son elementos de suma importancia en el proceso de aprendizaje. En las propuestas toman en cuenta las actividades "para leer con papá o mamá", estableciendo una corriente de comunicación hogar-escuela, donde los primeros permanecen junto a los niños durante todo el proceso. Además no olvidan destacar que la familia y el entorno los estimulan mucho antes del ingreso al Nivel Inicial.

* La mayoría de las docentes adaptan el conocimiento que poseen acerca de las diferentes teorías a cada situación de aprendizaje, seleccionando de éstas los aspectos que consideran más relevantes; otras en cambio mencionan estar de acuerdo con una concepción de aprendizaje que aplican en su quehacer diario.

\section{Con respecto a los alumnos:}

* Todos los niños reflejaron buena comunicación con sus docentes. La misma permitió que éstos demostraran interés en las actividades de Lectura propuestas.

*La mayoría de los niños de cuatro años leían sus propios nombres.

*La mayoría de los niños de cinco años podían leer los textos que se le presentaran.

\section{Con respecto a la ambientación de las aulas de clase:}

* Los ambientes son amplios y adecuados al tamaño de los alumnos. Todo está al alcance de sus manos. Esto favorece la labor educativa.

* Cada sala posee un rincón donde se encuentran diferentes materiales de lectura: libros de cuentos traídos por los niños, tarjetas con dibujos acompañadas de un texto, historietas, etc.

* En las salas hay también calendarios con los días de la semana, el mes y la estación del año que se actualizan día a día por los niños.

* Todas las salas cuentan con carteleras que muestran los diferentes trabajos de los alumnos. En las mismas se colocan carteles que explican el tema tratado.

\section{Reflexiones finales}


En el presente trabajo de investigación nos abocamos a un rastreo bibliográfico a fin de obtener un referente teórico que nos permitiera establecer lo que en materia de Lectura ha surgido en los últimos tiempos. Para ello iniciamos el marco teórico con una breve reseña de las concepciones más reconocidas, a fin de determinar los avances producidos en este campo, objeto de nuestro estudio.

Se pudo establecer que las características del niño de hoy incentivan a los docentes a incorporar las actividades de lectura en sus aulas. Hemos observado que los alumnos son los que promueven y exigen esas actividades y por eso la sala de clase se transforma en el mejor lugar para volcar sus inquietudes. En ella comparten sus intereses y aptitudes no sólo con su docente sino también con sus compañeros de clase, en un intercambio que produce una motivación que los lleva a buscar materiales y a investigar, para intentar leerlos para sí o para sus compañeros.

\section{Bibliografía}

BEHAR, R. 1997. La hora de aprender a leer. Montevideo. Rosgal.

CASTILLERO B., A 1992 Adquisiciones Básicas para el Aprendizaje de la Lectura y la Escritura Panamá. Instituto Universidad de Panamá - Instituto Centroamericano de Administración y Supervisión de la Educación (ICASE) .

COLL SALVADOR, C. 1992 Aprendizaje escolar y construcción del conocimiento Bs. As. Paidós.

DUBOIS, Ma E. 1987. El proceso de la lectura: de la Teoría a la práctica. Bs. As. Aique.

FERREIRO, E. 1988. Proceso de alfabetización- La alfabetización en proceso Bs. As. Centro Editor de América Latina.

FERREIRO, E.; TEBEROSKY, A. 1988. Los sistemas de escritura en el desarrollo del niño. México. Siglo XXI Editores.

GOODMAN, Y. 1991. Los niños construyen su lecto-escritura. Un enfoque piagetiano. Bs As. Aique.

HAMMERSLEY, M.; ATKINSON, P. 1994. Métodos de Investigación. Madrid. Paidós.

JOLIBERT, J. 1995 Formar niños lectores de textos. Santiago de Chile . Dolmen.

KAUFMAN, A.; CASTEDO, M.; TERUGGI, L.; MOLINARI, C. 1990 . Alfabetización de niños: construcción e intercambio. Bs. As. Aique.

KAUFMAN, A.; RODRÍGUEZ, M. E. 1993. La escuela y los textos. Bs As. Santillana

LERNER, D.; PALACIOS, A. 1994 . El aprendizaje de la lengua escrita en la escuela. Reflexiones sobre la propuesta pedagógica constructivista. Bs As. Aique.

LURÇAT, L. 1994 . “¿Qué es actualmente saber leer y escribir”. Revista Infancia No 27 setiembre - octubre 1994 páginas 26 - 28.

MEREGA, H. 1989. "Lecto-escritura inicial o ¿cómo hago para que mis alumnos de primer grado aprendan a leer y escribir?" una entrevista a Ana $\mathrm{M}^{\mathrm{a}}$ Kaufman. Bs.As. Santillana. 
PALACIOS, A., MUÑOZ, M.; LERNER, D. 1994 . Comprensión lectora y expresión escrita: Experiencia pedagógica. Bs As . Aique.

PÉREZ SERRANO, M. G. 1990. Investigación-Acción: aplicaciones al campo social y educativo. Madrid. Dykinson.

SANTOS, M. A. 1993 Hacer visible lo cotidiano. Madrid. Akal.

SMITH, F. 1990. Para darle sentido a la lectura. Madrid. Visor.

TAYLOR, S.J.; BOGDAN, R. 1996. Introducción a los métodos cualitativos de investigación. Bs.As. Paidós.

VIEYTES, M. y LÓPEZ, S. 1992. Experiencias de lecto-escritura en el Nivel Inicial. Bs. As . Actilibro. 